\title{
Government Size and Trade Openness: Some Additional Insights
}

\author{
Paolo Liberati ${ }^{1}$ \\ ${ }^{1}$ Department of Economics and CEFIP, University Roma Tre, Rome, Italy \\ Correspondence: Paolo Liberati, Department of Economics and CEFIP, University Roma Tre, Rome 00154, Italy. \\ E-mail: paolo.liberati@uniroma3.it \\ Received: April 25, 2013 \\ Accepted: May 29, 2013 \\ Online Published: June 30, 2013 \\ doi:10.5430/rwe.v4n2p12 \\ URL: http://dx.doi.org/10.5430/rwe.v4n2p12
}

\begin{abstract}
This paper provides additional insights on the relationship between government size and trade openness using a panel of countries drawn from the World Development Indicators and the Penn World Tables 7.0 from 1962 to 2009. It is shown that the compensation hypothesis proposed by Rodrik (1998) and revisited by Alesina and Wacziarg (1998) and by Ram (2009) cannot be attributed general validity. On the one hand, it is shown that country size is not relevant to determine the sign of the relationship between government size and economic openness, contradicting previous results by Alesina and Wacziarg (1998). On the other hand, the relevance of the cross-country heterogeneity suggested by Ram (2009) to argue in favour of the compensation hypothesis only picks the characteristic of the African countries of being relatively more closed.
\end{abstract}

Keywords: openness, government size, compensation hypothesis, government consumption, trade

\section{Introduction}

A body of influential research has suggested that there is a positive association between trade openness and government size. Cameron (1978), one of the first to establish econometric evidence on the topic, noted that trade openness in 1960 was a strong predictor of the increase in government tax revenues between 1960 and 1975 . He pointed out that more open countries tend to be more unionised, with collective bargaining leading to greater demand for social protection accommodated by increasing tax revenues. This pioneering version of the compensation hypothesis - by which more open countries tend to have bigger public sectors - was reappraised and further articulated by Rodrik (1998). While challenging the collective bargaining explanation, Rodrik argued that government spending might serve as an indirect insurance against external (and undiversified) risk. His most influential result was to find a positive association between government consumption and trade integration in a large sample of countries that qualifies openness both as a determinant and as a predictor of government consumption levels across countries (Rodrik, 1998; 1004). (Note 1) This conclusion would suggest a strong complementarity between markets and governments, with a more powerful role for government consumption in those economies that are subject to larger external risks.

In an influential work, Alesina and Wacziarg (1998) (henceforth AW) have challenged the Rodrik's hypothesis, by arguing that the positive relation between openness and government size could be mediated by country size. The first reason is that country size is negatively correlated to government size, as the costs of certain (non-rival) public goods grow less than proportionally to the size of population. This is typical, for example, of infrastructures, roads, libraries (at least up to the congestion limit) and implies that the per capita cost of public goods declines in larger countries. The second reason is that country size is also negatively correlated to trade openness, as small countries have less opportunity for autarky. As argued by AW (p. 306), these two facts taken together imply that more open countries may have bigger governments.

This has cast some doubts on the existence of a Rodrik-type direct link between openness and government size. Consistently with the two hypotheses, AW - by running OLS on 1980-84 averages for the same set of countries used by Rodrik (1998) - actually find a negative relation between government consumption and population (taken as a proxy of country size) and a negative relation between trade openness and population. In both cases, the $\log$ of population exhibits a highly significant negative coefficient, and the result appears robust not only to a parsimonious specification of explanatory variables, but also to an extension of the basic model to control for possibly omitted variables. 
Then, in order to capture the impact of country size on the co-variation between government consumption and trade openness, the authors move to the estimation of the basic Rodrik's specification, where country size is not included among the explanatory variables (as in Table 1 in Rodrik, 1998) and replicate the Rodrik's result of a positive association between government consumption and trade openness. By omitting trade openness and including country size the negative relation between country size and population is also confirmed. When including both (trade openness and country size), the positive impact of trade openness persists, that confirms the Rodrik's result. However, AW impute this persistence to the high degree of collinearity between openness and country size. Thus, they experiment a version of the regression where variables calculated as ratios are included in levels and not in logs. In this case, the positive relation between openness and government consumption disappears, showing that the original Rodrik's result might be driven by the omission of country size. (Note 2)

More recently, Ram (2009) (henceforth R) has challenged the outcome of AW mainly on the econometric ground. Considering 154 countries for the period 1960-2000, R shows that while pooled OLS regressions replicate the results of AW, a fixed effect estimation that takes into account cross-country heterogeneity would not lead to a significant negative co-variation of country size and either trade openness or government size (p. 213). Thus, the estimates by R would be consistent with a direct link between openness and government size along the lines suggested by Rodrik (1998), instead of being mediated by country size as argued by AW. In R, the compensation hypothesis would indeed be supported by the positive sign of trade in all specifications.

This paper sheds additional light on these issues. In particular, it will compare the results by AW and R with those obtained by an updated panel analysis in the period 1962-2009, with data taken from the Penn World Tables 7.0 (PWT) and from the World Development Indicators (WDI). We show that the sign of the relationship between government size and economic openness is not necessarily driven by country size. More importantly, the results obtained by fixed effects as in Ram (2009) show that the compensation hypothesis strictly depends on the inclusion of African countries, further weakening the general validity of the compensation hypothesis.

\section{Econometric Strategy and Data}

In order to update the analysis by AW and R and to compare our estimates with their previous results, we start from the same set of parsimonious equations:

$$
\begin{aligned}
& G O V_{i t}=\alpha+\beta_{1} S_{Z Z E_{i t}}+\beta_{2} Y_{i t}+u_{i t} \\
& \operatorname{TRADE} i t=\gamma+\beta_{3} \operatorname{SIZE}_{i t}+\beta_{4} Y_{i t}+\varepsilon_{i t} \\
& G O V_{i t}=\delta+\beta_{5} \mathrm{TR} A D E_{i t}+\beta_{6} Y_{i t}+v_{i t}
\end{aligned}
$$

where $Y_{i t}$ is the PPP converted per capita GDP used as a common control variable in all regressions to be homogeneous with both $\mathrm{AW}$ and R. The first equation considers the relation between the share of government consumption over GDP at 2005 constant prices (GOV) and country size (SIZE, approximated by total population). Government consumption excludes interest payments, transfers and public investments, while it includes the monetary value of in-kind publicly provided goods and services (e.g., health and education). The second equation introduces the relation between trade openness (TRADE), defined by the share of exports and imports over GDP at 2005 constant prices, and country size, while equation (3) gives the relation between trade openness and government consumption. It is worth noting that the parsimonious specification - which excludes other control variables - is adopted in order to make our analysis as closest as possible to both AW and R.

In equation (1), $\beta_{1}<0$ would suggest lower government consumption in larger countries. As argued by AW, this 'income effect' would be driven by the lower per capita cost of the public good provision, which would raise the opportunities for more private consumption. Yet, if there is a certain degree of substitutability between private and public goods, a reduction of the 'price' of public goods may lead to additional government consumption and to $\beta_{1}>0$. In equation (2), $\beta_{3}<0$ would rationalise the intuition that smaller countries, in a regime of trade liberalisation, are not necessarily smaller markets, as the political borders do not identify the size of the market (AW; 306); larger countries, instead, have more opportunity for 'autarky'. Equation (3), instead, gives a simplified picture of the Rodrik's (1998) 
position. In this case, $\beta_{5}>0$ would support the compensation hypothesis, i.e. the case where more exposure to international trade would lead to higher government consumption, while $\beta_{5}<0$ would support the efficiency hypothesis, i.e. the case where economic openness introduces a constraint on public spending.

In what follows, under appropriate specifications of the previous set of equations and using similar econometric techniques, we will be able to replicate most of the results obtained by AW and R, but also to provide some additional insights. In particular, we will first show that the relationship between government size and openness is not necessarily mediated by country size. Second, we show that those outcomes strongly depend on the presence of a specific geographical area and cannot thus easily be generalised.

Data used in the analysis are mainly taken from the World Development Indicators (WDI) and from the Penn World Tables (PWT). The unbalanced panel needed to compare our results with AW and R, consists of a maximum of 156 countries variously observed between 1962 and 2009, which also make the results comparable with more recent contributions on the topic (e.g., Kimakova, 2009). (Note 3)

\section{Results}

\subsection{Similarities and Differences with $A W$ and $R$}

AW show that the compensation hypothesis is confirmed only when population is not included among the regressors (as originally formulated by Rodrik, 1998). When equation (3) is augmented with population and variables are entered in levels, the positive relationship between openness and government consumption disappears. As stated by AW (p. 318 ), this would imply that "... the effect of openness on government size is largely driven by the omission of country size ...". This result, however, has been attributed by R to the lack of cross-country heterogeneity in the pooled OLS regression performed by AW. By introducing a fixed effect estimator, R shows that the positive relationship comes back even after controlling for population size, restoring the validity of the compensation hypothesis.

The first panel of table 1 reports our estimations by OLS and fixed effects of equations (1) to (3). All variables are expressed in logs (if not otherwise stated), while the significance level is calculated using the White's (1980) heteroskedastic standard errors. Consider first equation (1) (the relationship between government size and population) as reported in columns A and B. OLS on pooled data are consistent with the corresponding outcomes in both AW and $\mathrm{R}$ (whose signs and statistical significance are reported in rows Population in $A W$ and Population in $R$ ), suggesting that lower government consumption is associated to larger countries. Moving to fixed effects (henceforth FE) gives in R a positive and statistically significant coefficient (AW does not perform FE), which contradicts the relationship between the two variables identified by pooled OLS. In our estimates, instead, the coefficient is of the same sign as in pooled OLS, and still statistically significant. (Note 4)

With regard to equation (2) (the relationship between trade openness and population), the maintained hypothesis is that larger countries are less open (columns $\mathrm{C}$ and D). Our estimations with OLS are again in line with this intuition (the coefficient is negative and statistically significant) and in line with the results by AW and R. The same outcome as in R is also obtained when using FE (a coefficient that is not statistically significant).

Consider now equation (3) (the relationship between government size and trade openness) when population is not included among the control variables (column E). OLS estimates give an outcome that is consistent with AW, and would still be consistent with the possibility that the compensation hypothesis may be driven by the omission of country size. When including country size (columns G), AW shows that the compensation hypothesis is true when ratios are entered in logs, while it is not true when ratios are entered in levels. Our OLS estimates, instead, reveal that the compensation hypothesis could be supported in both cases. Both estimations with fixed effects are instead in line with $\mathrm{R}$ (columns $\mathrm{F}$ and $\mathrm{H}$ ), which means that the compensation hypothesis survives the inclusion of population among the regressors. Thus, in our estimates, the compensation hypothesis does not seem mediated by country size in neither case, as suggested by AW. This outcome confirms the original results by R that cross-country heterogeneity may best explain the presence of the compensation hypothesis and excludes the case that the omission of country size is a fundamental driver of it, even after extending the analysis to 2009 .

In order to check whether the compensation hypothesis is robust to alternative specifications, FE estimation has been replicated using two transformed datasets. The first includes all 156 countries, with variables expressed as a 5-year moving average of the original ones. The second is to use a 5-year average of the relevant variables for that subset of countries forming a balanced panel dataset (from 1979 to 2008). Both strategies have the aim of weeding out short-term fluctuations of the variable. A third alternative is to use lagged explanatory variables to deal with a potential endogeneity problem. In all cases, the coefficient of trade in equation (3) - in both versions - is positive and 
statistically significant (in one case the significance level is slightly above 5 per cent), an outcome that supports the compensation hypothesis.

Table 1. Pooled and fixed effects: a comparison with AW and R

\begin{tabular}{|c|c|c|c|c|c|c|c|c|}
\hline & \multicolumn{2}{|c|}{$\begin{array}{c}\text { Government } \\
\text { consumption } \\
\text { Equation (1) }\end{array}$} & \multicolumn{2}{|c|}{ Trade } & \multicolumn{2}{|c|}{$\begin{array}{l}\text { Government consumption } \\
\text { (population not included) }\end{array}$} & \multicolumn{2}{|c|}{$\begin{array}{c}\text { Government } \\
\text { consumption (population } \\
\text { included) } \\
\text { Equasion (3) }\end{array}$} \\
\hline & $\begin{array}{r}\text { Pooled } \\
\text { (A) }\end{array}$ & $\begin{array}{l}\mathrm{FE} \\
\text { (B) }\end{array}$ & $\begin{array}{r}\text { Pooled } \\
\text { (C) }\end{array}$ & $\begin{array}{l}\mathrm{FE} \\
\text { (D) }\end{array}$ & $\begin{array}{r}\text { Pooled } \\
(E)\end{array}$ & $\begin{array}{l}\mathrm{FE} \\
(\mathrm{F})\end{array}$ & $\begin{array}{r}\text { Pooled } \\
(G)\end{array}$ & $\begin{array}{l}\text { FE } \\
(\mathrm{H})\end{array}$ \\
\hline \multicolumn{9}{|l|}{ Al/ countries } \\
\hline Population & $-0.077=$ & $-0.508=$ & $-0.189=$ & -0.019 & & & & \\
\hline Trade in logs & & & & & $0.257 *$ & $0.097 *$ & $0.151 *$ & $0.094 *$ \\
\hline Trade in levels & & & & & $0.317 *$ & 0.048 & $0.142=$ & 0.033 \\
\hline Number of countries & & 156 & & 156 & & 156 & & 156 \\
\hline Number of observations & 4909 & 4909 & 4909 & 4909 & 4909 & 4909 & 4909 & 4909 \\
\hline Population in AW & $-0.795=$ & & $-13.91 *$ & & & & & \\
\hline Population in $R$ & $-0.080=$ & $0.475=$ & $-0.205=$ & 0.032 & & & & \\
\hline Trade in AW in logs (a) & & & & & $0.190=$ & & $0.152 *$ & \\
\hline Trade in AW in levels (a) & & & & & $0.031=$ & & 0.008 & \\
\hline Trade in $R$ (b) & & & & & $0.244=$ & $0.081 *$ & & $0.155 *$ \\
\hline \multicolumn{9}{|l|}{ Moving averages 5-year period } \\
\hline Population & & $-0.527=$ & & -0.020 & & & & \\
\hline Trade in logs & & & & & & $0.112=$ & & $0.109=$ \\
\hline \multicolumn{9}{|l|}{ 5-year averages (c) } \\
\hline Population & & $-0.357=$ & & 0.255 & & & & \\
\hline Trade in logs & & & & & & $0.122=$ & & 0.142 * \\
\hline \multicolumn{9}{|l|}{ Lagged explanatory variables } \\
\hline Trade in logs & & & & & & $0.105=$ & & $0.104=$ \\
\hline \multicolumn{9}{|l|}{ Excluding African countries } \\
\hline Population & $-0.069=$ & $-0.364=$ & $-0.185=$ & 0.068 & & & & \\
\hline Trade in logs & & & & & $0.231=$ & 0.006 & $0.118=$ & 0.021 \\
\hline Trade in levels & & & & & $0.283=$ & -0.051 & $0.105=$ & -0.045 \\
\hline Number of countries & & 109 & & 109 & & 109 & & 109 \\
\hline Number of observations & 3355 & 3355 & 3355 & 3355 & 3355 & 3355 & 3355 & 3355 \\
\hline \multicolumn{9}{|l|}{ Moving averages 5-year period } \\
\hline Population & & $-0.349=$ & & 0.178 & & & & \\
\hline Trade in logs & & & & & & 0.015 & & 0.034 \\
\hline \multicolumn{9}{|l|}{ 5-year averages (c) } \\
\hline Population & & -0.101 & & $0.527 \approx=$ & & & & \\
\hline Trade in logs & & & & & & 0.019 & & 0.031 \\
\hline \multicolumn{9}{|l|}{ Lagged explanatory variables } \\
\hline Trade in logs & & & & & & 0.019 & & 0.033 \\
\hline Trade excluding American countries (125) & & & & & & 0.132 * & & $0.106 *$ \\
\hline Trade excluding Asian countries (126) & & & & & & $0.115 *$ & & $0.110 *$ \\
\hline Trade excluding European countries (116) & & & & & & $0.107=$ & & $0.108=$ \\
\hline Trade excluding Pacific countries (141) & & & & & & $0.094=$ & & $0.090=$ \\
\hline
\end{tabular}

Note: All regressions include PPP converted GDP per capita and year dummies

(a) This outcome is obtained in AW in a regression that includes other control variables

(b) The coefficient obtained with FE when populason is included (last column) is obtained by Ram with a regression on 10-year averages

(c) 76 countries for the period 1979-2008, balanced panel

* indicates a significance level of at least 5 per cent

* indicates a 10 per cent level significance level

Source: Author's elaborations on PWT and WDI data

\subsection{Sensitivity to Geographical Areas}

It is worth now exploring the robustness of the conclusion by R that cross-country heterogeneity is the best explanation to assign general validity to the compensation hypothesis. The reason for this geographical investigation is that the available empirical studies often include a large number of countries, with deep political and institutional differences, as well as large gaps in average incomes and the size of the public sector. Thus, a uniform behaviour of the relationship between government consumption and trade openness cannot be taken for granted. This suggests analysing whether specific groups of countries or world regions may drive the compensation hypothesis. 
The second panel of table 1 shows that this is the case. In particular, the presence of the compensation hypothesis seems to be driven by the presence of African countries. The most striking result is that while the first two relationships are not affected (columns A to D), the core relationship between government size and trade openness undergoes a fundamental change. Indeed, while estimations with pooled OLS (columns E and G) are fully comparable to the previous ones even after excluding African countries, estimations with FE (columns F and H) are no longer sufficient to guarantee the generalised persistence of the compensation hypothesis. Indeed, with or without population, the coefficient of trade openness is not statistically significant. This also holds for alternative specifications with 5-year moving average, 5-year averages (where 19 African countries are removed from the balanced panel) and lagged explanatory variables. This means that the positive and significant effect found by $\mathrm{R}$ and replicated by our estimates in the case of all countries is not driven by a generalised cross-country heterogeneity, but only by the cross-country heterogeneity of African countries compared to the rest of the world.

In order to check for the robustness of this result, FE estimation is replicated by excluding other continents one at a time. The outcome is reported in columns $\mathrm{F}$ and $\mathrm{H}$ at the bottom of the table. One can see that all coefficients are statistically significant. (Note 5) This implies that the inclusion of African countries is a sufficient condition to generate the validity of the compensation hypothesis, while its exclusion denies its general validity. In other terms, observations on African countries are influent, which means that they can be seen as a structural break in the overall relationship between government consumption and trade openness. (Note 6)

To some extent, the power of African countries as a driver of the compensation hypothesis is not very surprising if one considers the year in which uninterrupted trade openness began in many countries of the continent. According to the most recent data provided by Wacziarg and Horn Welch (2008), 8 out of 47 African countries included in the analysis are still classified as "closed" to international trade, (Note 7) and other seven countries date their trade openness just after 1995. (Note 8) Thus, almost 1/3 of African countries have been "closed" for most of the time they are observed in the dataset; furthermore, on a total of 44 countries (out of 91 surveyed by Wacziarg and Horn Welch, 2008) that opened to trade after 1991, 25 in total are African countries. These numbers cast some doubts on how these countries could be confidently used to support the compensation hypothesis in the absence of the institutional conditions in which this hypothesis should work (i.e. formal openness). In our view, the relationship between government size and trade openness cannot safely be assumed to behave in Africa as in other geographical areas where formal trade openness is more developed, and should merit a separate treatment. More generally, empirical works on this topic should more carefully analyse the variety of institutional characteristics associated to different geographical areas.

This outcome is particularly important, if matched with the perception that econometric analyses with a larger number of countries are more often in favour of the compensation hypothesis (Gastaldi and Liberati, 2011). Generalisations of this outcome should therefore be assessed with extreme caution in the light of the present results. We have shown that country size is to some extent irrelevant to determine the sign of the relationship; while cross-country heterogeneity only picks some specific characteristics of the African countries, that of being relatively more closed and therefore unsuitable to defend the compensation hypothesis.

\section{Conclusions}

This paper has provided additional insights to understand the relationship between government size and economic openness. On the one hand, it is shown that country size is not relevant to determine the sign of the relationship between government size and economic openness, contradicting previous results by Alesina and Wacziarg (1998). On the other hand, the relevance of the cross-country heterogeneity suggested by Ram (2009) to argue in favour of the compensation hypothesis only picks the characteristic of the African countries of being relatively more closed. As a consequence, the compensation hypothesis cannot be assigned general validity on this ground. This result is also robust to alternative specifications of the explanatory variables.

\section{References}

Alesina, A., \& Wacziarg, R. (1998). Openness, Country Size and Government. Journal of Public Economics, 69, 305-321. http://dx.doi.org/10.1016/S0047-2727(98)00010-3

Gastaldi, F., \& Liberati, P. (2011). Economic Integration and Government Size: A Review of the Empirical Literature. Financial Theory and Practice, 35, 327-384.

Kimakova, A. (2009). Government Size and Openness Revisited: the Case of Financial Globalization. Kyklos, 3, 394-406. http://dx.doi.org/10.1111/j.1467-6435.2009.00442.x

Ram, R. (2009). Openness, Country Size and Government Size: Additional Evidence from a Large Cross-Country Panel. Journal of Public Economics, 93, 213-218. http://dx.doi.org/10.1016/j.jpubeco.2008.04.009 
Rodrik, D. (1998). Why Do More Open Economies Have Bigger Governments? Journal of Political Economy, 106, 997-1032. http://dx.doi.org/10.1086/250038

Wacziarg, R., \& Horn, Welch K. (2008). Trade Liberalization and Growth: New Evidence. The World Bank Economic Review, 22, 187-231. http://dx.doi.org/10.1093/wber/lhn007

\section{Notes}

Note 1. In Rodrik (1998), a measure of the risk involved in higher economic integration was taken as the product between volatility of terms-of-trade and trade openness.

Note 2. AW do not apparently take into account that Rodrik (1998) shows the persistence of the positive sign of the coefficient of trade openness also in alternative cases, and that the positive sign is robust to the introduction of two proxies of country size, i.e. land area and population. The main difference between AW and Rodrik (1998) would therefore lie in the contrasting outcome emerging in $\mathrm{AW}$ when the regression is not estimated in logs.

Note 3. The nature of the panel (unbalanced) means that not all countries are observed in all years. Even though it is not explicitly stated, unbalancing must occur also in $\mathrm{R}$, where the product between the number of countries declared (154) and the years observed (41) should provide 6,314 observations. However, in tables only 5,117 observations are reported, which means about 81 per cent of the potential total number of observations. In our case, after extending to 2009 , this percentage is quite similar (81.6 per cent). The distribution of countries across years in $\mathrm{R}$ is however not known. Thus, it is not possible to check whether our countries match with the original 154 in R.

Note 4. The difference identified by $\mathrm{R}$ is hardly explainable, especially if one takes into account that all other results in our estimations are strongly similar to R. Even though the two regressions have different temporal extensions, a replication of the regression from 1962 to 2000 (which is the upper limit also used in Ram, 2009) gives the same sign (negative instead of positive as in R), with no apparent deviation (not reported in table). By replicating the regression splitting the sample between African and non-African countries also gives negative and statistically significant sign in all cases.

Note 5. When excluding Oceania and America and using FE, the significance level is just over 5 per cent (5.4 and 5.1 per cent, respectively).

Note 6. By performing a Chow test on the regression between government consumption and trade, the null hypothesis of stability is rejected. The hypothesis that these countries can drive the relationship between the two variables finds therefore additional support.

Note 7. They are: Central African Republic; Lesotho; Liberia; Nigeria; Togo; Gabon; Algeria; Congo; Malawi; Senegal; Swaziland. The total number of closed countries is 29.

Note 8. They are: Egypt; Ethiopia; Madagascar; Mozambique; Tanzania; Mauritania; Sierra Leone. 